\title{
THE MECHANICAL AND MICROSTRUCTURAL STUDY OF WELDED AA7075 USING DIFFERENT FILLER METALS
}

\author{
M. ISHAK, M.N.M. SALLEH \& S.R. AISHA \\ Faculty of Mechanical Engineering, Universiti Malaysia Pahang, Malaysia.
}

\begin{abstract}
This paper discussed about the consequences of using different filler metal by metal inert gas (MIG) welding process on aluminium alloys Al 7075 sheet metal joint. Nowadays, Al 7075 is widely used in automobile and aviation industry due to its light weight, strong, and high hardness. Fusion welding, such as MIG and TIG were commonly used in joining the aluminium alloys due to its low cost. However, defects usually occurred using fusion welding because of the inaccurate welding parameters and types of filler metal used. The purpose of this study is to determine whether the filler metal with different elements and welding parameters affect the mechanical properties of welded $\mathrm{Al} 7075$. Welding parameters used were current, voltage, welding speed, and Argon (Ar) as shielding gas. Two different types of filler metal were used which is Electrode Rod (ER) 4043 and ER5356 which is from Al-Si and Al-Mg based element, respectively. From microstructure analysis, fusion zone (FZ) of sample welded with ER4043 has a smaller grain size than that of with ER5356. Both filler produced equiaxed dendritic grain at FZ. Both samples welded with ER4043 and ER5356 has lower hardness value than heat affected zone (HAZ) and base metal (BM) due to the differences in their elements where ER4043 from Al-Si and ER5356 from Al-Mg group. The weld efficiency of sample welded using ER5356 was 61\% which was higher compared to sample welded using ER 4043 which at $43 \%$ and both sample was brittle fractured. Sample welded with ER5356 was fractured at HAZ due to porosity while sample welded with ER4043 fractured at FZ due to the oxide inclusion.
\end{abstract}

Keywords: Al 7075, ER4043, ER5356, mechanical properties, microstructure analysis MIG.

\section{INTRODUCTION}

In recent years, there has been an increasing amount of literature on welding Aluminium Alloys 7075 (Al-Zn-Mg). This metal has been utilized throughout aircraft and aerospace structure and it is heat treatable and the strongest and hardest aluminium alloys [1]. Al 7075 was largely used in automobile and aerospace industry $[2,3]$. For a car, the parts usually used this metal are connecting rod, axle shaft, rims, as metals in the bumpers and door beams [4]. For the aerospace industry, usually Al 7075 sheet is used largely for aircraft body and used for fuel tank in the spacecraft. This is due to its characteristics which are light weight, strong and high hardness and also has good machinability [5].

Tungsten Inert Gas (TIG) and Metal Inert Gas (MIG) were mostly used in joining the process of aluminium alloys [6-10], but MIG welding method was preferable since it is widely used for welding aluminium and it produces good weld appearance and quality [7]. Filler metal plays important role in fusion welding since the selection of filler metal type can affect the welded joint. The 7N01 alloys of 7000 series aluminium alloys with other aluminium alloys such as 5000 and 6000 series where they are applicable as structural material in the automobile sector had been welded with filler wire ER5356 using Direct Current Electrode Positive-Metal Inert Gas (DCEP-MIG) welding method $[4,7,11]$. This means that the 
common filler wire used to weld aluminium alloys is ER5356 (Al-Mg). The joining method used for this study is DCEP (Pulse) MIG. To the best of author knowledge, no report has been found so far using a different filler rod to weld Al 7075 using MIG welding method. Yet, it is far too little discussion about the effect of different filler which has different alloying element with Al 7075 base metal. So, it is necessary to carry out deep research on the effects of different types of filler metal used to weld Al 7075 by MIG welding technique.

This objective of the present work is to compare Al 7075 welded joint for its mechanical properties and microstructure behaviour when welded with different type of filler metal. Besides, this study is also an attempt to investigate the fracture behaviour when welded with ER4043 and ER5356. In addition, the paper also seeks for the weld defect produced after being welded by these fillers. The welded 7075 aluminium alloys joint will undergo mechanical testing such as Vickers hardness and tensile test as well as microstructure analysis in order to characterize the microstructure behaviour after welded by ER4043 and ER5356.

\section{EXPERIMENTAL PROCEDURES}

Al 7075 with 2 mm thickness was used in this present work. Table 1 shows the chemical composition of $\mathrm{Al} 7075$ as well as filler wires. It was shown that the percentage weight (wt\%) of elements in the Al 7075 and filler rod ER4043 and ER5356 were different. The Al 7075 possess $\mathrm{Zn}$ and $\mathrm{Mg}$ elements as the major alloying element with $5.58 \%$ and $2.28 \%$, respectively, whereas ER4043 showed that $\mathrm{Si}$ was the alloying element with $6.0 \%$ and ER5356 showed that $\mathrm{Mg}$ was the alloying element with $5.5 \%$. Al 7075 was cut by dimension of $150 \times 150 \times$ $2 \mathrm{~mm}$. The ASTM E8 tensile test samples were produced through the machining process by CNC milling machine. Tensile test parameter was fixed such as speed at $0.083 \mathrm{~mm} / \mathrm{s}$ and load at $50 \mathrm{kN}$ and it does not affect the UTS. Then, welded samples were hot mounted for microstructure observation and Vickers' hardness testing. The results of tensile test were recorded in order to compare the strength between the parent metal Al 7075 with the $\mathrm{Al} 7075$ welded using ER5356 and ER4043. An optical microscope was used to observe the microstructure behaviour of welded specimen at welded cross section. Weld defect was also observed on the welded surface from the macrostructure image. Based on Box-Behnken design with full replication and 1 center points, 14 welded samples needed for each experiment and due to the

Table 1: Chemical composition of A1 7075 aluminium alloys and filler wire.

\begin{tabular}{llll}
\hline & \multicolumn{2}{l}{ Composition (wt\%) } & \\
\cline { 2 - 4 } Element & Al 7075 & ER4043 & ER5356 \\
\hline $\mathrm{Mg}$ & 2.28 & 0.05 & 5.50 \\
$\mathrm{Zn}$ & 5.58 & 0.10 & 1.00 \\
$\mathrm{Si}$ & 0.07 & 6.00 & 0.25 \\
$\mathrm{Fe}$ & 0.27 & 0.80 & 0.40 \\
$\mathrm{Cu}$ & 1.60 & - & - \\
$\mathrm{Mn}$ & 0.02 & - & - \\
$\mathrm{Al}$ & Bal. & Bal. & Bal. \\
\hline
\end{tabular}


Table 2: Welding condition.

\begin{tabular}{ll}
\hline Working Parameter & Description \\
\hline Process & DCEP-Pulse MIG welding \\
Shielding Gas & $25 \mathrm{~L} / \mathrm{min}-\mathrm{Ar}$ \\
Workpiece Dimension & Al 7075-150 × $150 \times 2 \mathrm{~mm}$ \\
Filler Metal & ER4043, ER5356(1.0 mm-diam) \\
Current & $105-115$ A (4043) \\
& $100-110$ A $(5356)$ \\
Voltage & $17.5-18$ V (4043) \\
& $16.0-20 \mathrm{~V}(5356)$ \\
Welding Speed & $3-5 \mathrm{~mm} / \mathrm{s}(4043)$ \\
& $2-4 \mathrm{~mm} / \mathrm{s}(5356)$ \\
\hline
\end{tabular}

differences in chemical composition of filler metal, the range of parameters used for current, voltage, and welding speed were varied. The lists of experimental parameters were tabulated in Table 2.

\section{RESULT AND DISCUSSION}

\subsection{Microstructure analysis}

Figure 1 shows the microstructure of welded Al 7075 cross section at three different locations using filler rod ER5356 and ER4043. For base metal (BM) microstructure, it was revealed that the spheroidal particles which were the black precipitates represented the MgZn elements and the light grey particles represented the $\mathrm{FeAl}_{3}[12]$. The findings provide the evidence that the grains elongated horizontally only in one direction. It was found that the equiaxed dendritic network grain presented at FZ of both samples welded by ER4043 and ER5356. The grain size at FZ was different for both samples. The average grain size from 20 readings for FZ, HAZ, and BM was presented in Table 3. Apparently, the grain size in FZ for ER5356 was larger compared to the grain size for ER4043 with $99.50 \mu \mathrm{m}$ and $92.58 \mu \mathrm{m}$, respectively. The microstructure at partially melted zone (PMZ) which was the transition region between the FZ and HAZ was typical coarse columnar grain [13]. This was due to the zone deteriorated by heat of welding during melting and solidification process [7]. The more surprising correlation is there was an increasing of 4.4\% in average grain size in sample welded with ER5356 with 95.28 and $99.5 \mu \mathrm{m}$ in FZ and HAZ, respectively.

\subsection{EDX analysis}

The energy dispersive X-ray (EDX) with spot analysis on FZ, HAZ and BM of welded Al 7075 using fillers ER4043 and ER5356 has been conducted. The data of element concentration for base metal were collected in Table 4. Figure 2 shows the spot EDX analysis of Al 7075 base metal. The atomic percentage of $\mathrm{Al}$ and $\mathrm{Cu}$ was found to be much higher than the other elements shown in Table 4. Whereas the silverish spot occurred due to the existence of Al-Cu compound 
a.

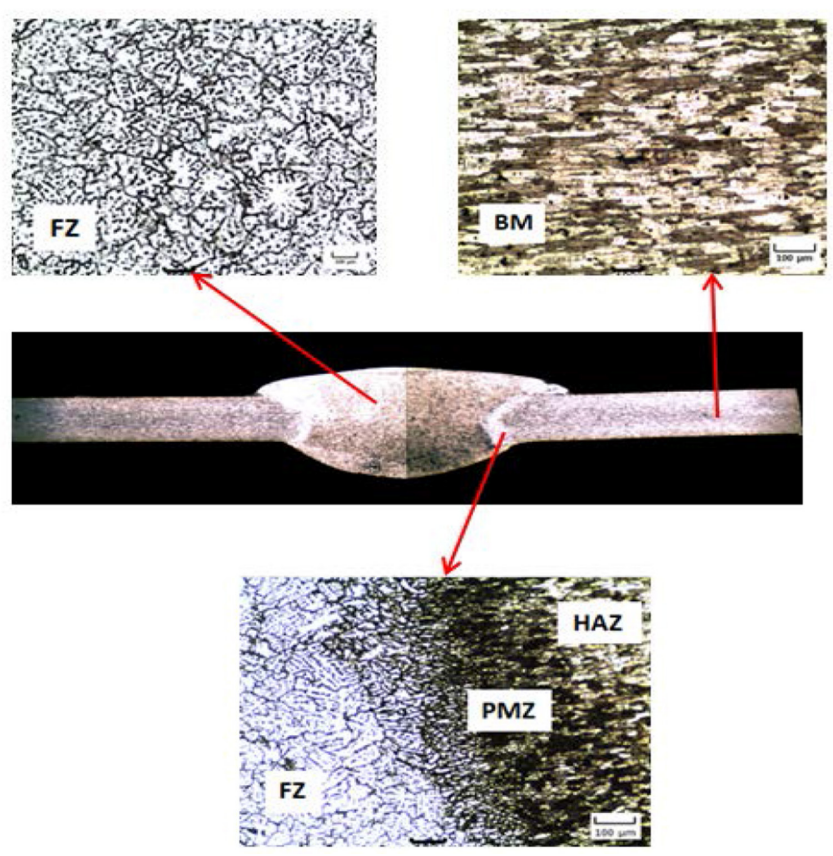

b.

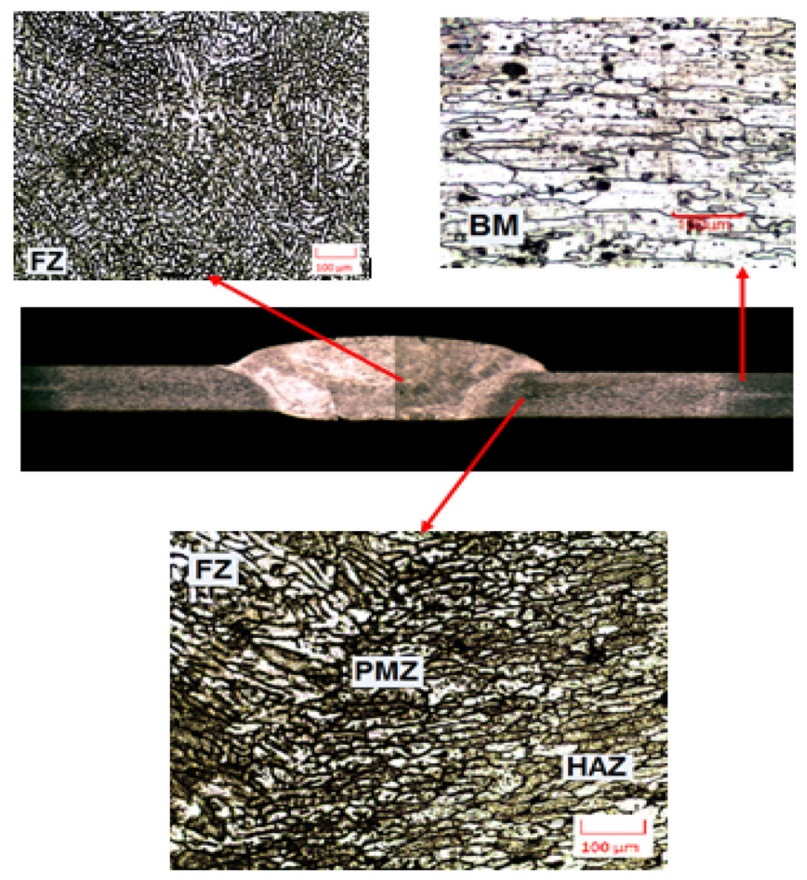

Figure 1: Microstructure image of welded cross section a. Al 7075 with ER5356 b. Al 7075 with ER4043. 
Table 3: Average grain size of microstructure.

\begin{tabular}{lll}
\hline \multirow{2}{*}{ Region } & \multicolumn{2}{l}{ Average Grain Size $(\mu \mathrm{m})$} \\
\cline { 2 - 3 } & ER5356 & ER4043 \\
\hline Fusion Zone (FZ) & 99.50 & 32.58 \\
Heat Affected Zone (HAZ) & 95.28 & 95.34 \\
Base Metal (BM) & 131.24 & 131.20 \\
\hline
\end{tabular}

Table 4: Element concentration for Al 7075 base metal.

\begin{tabular}{lllllll}
\hline \multirow{2}{*}{ Point } & \multicolumn{6}{l}{ Elements concentration $(\%)$} \\
\cline { 2 - 7 } & $\mathrm{Al}$ & $\mathrm{Zn}$ & $\mathrm{Mg}$ & $\mathrm{Cu}$ & $\mathrm{Fe}$ & $\mathrm{Si}$ \\
\hline 1 & 41.1 & 1.3 & 1.3 & 33.0 & 8.0 & 2.0 \\
2 & 90.9 & 4.2 & 3.5 & - & - & 1.4 \\
3 & 90.3 & 4.0 & 3.4 & - & - & 1.6 \\
\hline
\end{tabular}

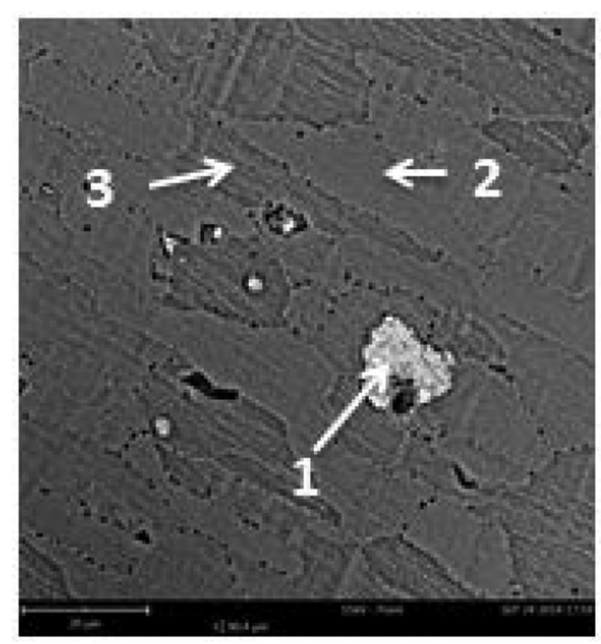

Figure 2: EDX spot analysis of Al 7075 base metal.

presented in $\mathrm{Al}$ 7075. In addition, point 2 and 3 shows a higher percentage of $\mathrm{Zn}$ element with the average value of $4.1 \%$ and $\mathrm{Mg}$ element with $3.45 \%$. These elements were found in $\mathrm{Al}-\mathrm{Zn}-\mathrm{Mg}$ compound. From this result, it was proven that the sample used in this experiment was $\mathrm{Al} \mathrm{7075,} \mathrm{which} \mathrm{is} \mathrm{Al}-\mathrm{Zn}-\mathrm{Mg}-\mathrm{Cu}$ aluminium alloy. Data from this table can be compared with the data in Table 1 which shows the value of element concentration approximately same. As Figure 2 shows, it was observed that there was no Inter-Metallic Compound (IMC) formation in BM of $\mathrm{Al} 7075$ as the percentage of element found was the original element in this metal. 
Table 5 shows the result of element concentration percentage and Figure 3 shows the EDX image at FZ and HAZ for sample welded with filler ER5356. In Figure 3a, the silverish spot labelled as point 1 has the atomic percentage of $\mathrm{Cu}$ element with $47.1 \%$ (highest), $\mathrm{Al}$ is 45.9 (2nd highest), and $\mathrm{Mg}$ is $2.8 \%$ (3rd highest) as shown in Table 5. In addition, it was found that $\mathrm{Cu}_{\mathrm{m}} \mathrm{Al}_{\mathrm{n}}$ compound presented high at point 1 , while point 2 shows the black spot which only had an atomic percentage of $\mathrm{Al}$ elements with $95.1 \%$ (highest) and $\mathrm{Mg}$ with $4.9 \%$. The black spot was proven to be the Al-Mg element. Meanwhile point 3 shows the light grey spot which also only has $\mathrm{Al}$ and $\mathrm{Mg}$ elements. It was found that the particles of $\mathrm{Al}-\mathrm{Mg}$ elements had the majority area from Figure $3 \mathrm{a}$ and a small amount of $\mathrm{Cu}_{\mathrm{m}} \mathrm{Al}_{\mathrm{n}}$ compound presents in the FZ. It was proven that some compound of $\mathrm{Cu}_{\mathrm{m}} \mathrm{Al}_{\mathrm{n}}$ presented in $\mathrm{FZ}$ was due to the IMC formation because $\mathrm{Cu}$ element was originally from $\mathrm{BM}$ element since it was not presented as the alloying element in ER5356. Other than that, in Figure 3b, point 4 shows silverish spot which has an atomic percentage of $\mathrm{Al}$ with $43.3 \%$ (highest), $\mathrm{Cu}$ with $19.3 \%$ (2nd highest), $\mathrm{Fe}$ with $9.9 \%$ (3rd highest), and $\mathrm{Zn}$ with $4.4 \%$ (4th highest). It was found that point 4 consists of $\mathrm{Fe}_{\mathrm{m}} \mathrm{Al}_{\mathrm{n}}$ compound and $\mathrm{Cu}$ element was a typical alloying element for $\mathrm{Al}$ 7075. Point 5 shows dark grey part in HAZ which has Al with $95.0 \%$ (highest), Zn with 3.5\% (2nd highest), and $\mathrm{Mg}$ with $1.5 \%$ (3rd highest). It was proven that the element presented in point 5 was

Table 5: Element concentration for welded A1 7075 using filler ER5356.

\begin{tabular}{lllllll}
\hline \multirow{7}{*}{ Point } & \multicolumn{6}{l}{ Elements concentration $(\%)$} \\
\cline { 2 - 7 } & $\mathrm{Al}$ & $\mathrm{Zn}$ & $\mathrm{Mg}$ & $\mathrm{Cu}$ & $\mathrm{Fe}$ & $\mathrm{Si}$ \\
\hline 1 & 45.9 & - & 2.8 & 47.1 & - & - \\
2 & 95.1 & - & 4.9 & - & - & - \\
3 & 95.6 & - & 4.4 & - & - & - \\
4 & 43.3 & 4.4 & 1.8 & 19.3 & 9.9 & 2.4 \\
5 & 95.0 & 3.5 & 1.5 & - & - & - \\
6 & 97.2 & - & 2.8 & - & - & - \\
\hline
\end{tabular}

a.

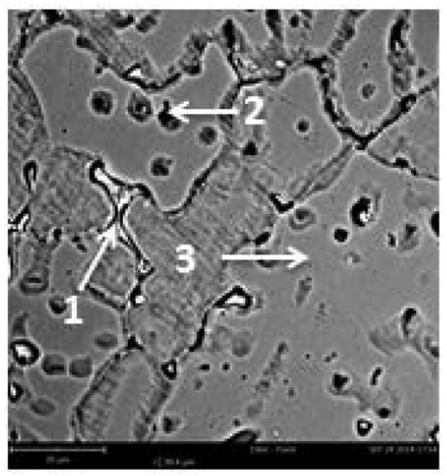

b.

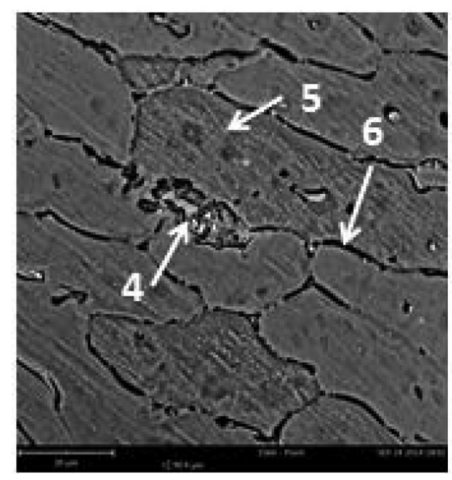

Figure 3: EDX spot analysis sample with ER5356 a. Fusion Zone b. Heat Affected Zone. 
$\mathrm{Al}-\mathrm{Zn}-\mathrm{Mg}$ which actually the same element as the parent metal. Last but not least, point 6 shows the black spot which has a higher $\mathrm{Mg}$ concentration at $2.8 \%$ after $97.2 \%$ of $\mathrm{Al}$ (highest). The EDX analysis for sample welded with filler ER5356, the element found in FZ was $\mathrm{Al}-\mathrm{Mg}$ which came from ER5356 element. At HAZ, the grey part was the majority area and it is from $\mathrm{Al}-\mathrm{Zn}-\mathrm{Mg}$ which is the base metal element with a few presents of $\mathrm{Fe}_{\mathrm{m}} \mathrm{Al}_{\mathrm{n}}$ compound due to the existence of atomic percentage of Fe element in both filler rod and parent metal with $0.4 \%$ and $0.27 \%$, respectively.

Table 6 shows the result of the element concentration percentage, while Figure 4 presents EDX image at FZ and HAZ for sample welded with filler ER4043. From Figure 4a, point 1 in the $\mathrm{FZ}$ shows the atomic percentage of $\mathrm{Al}$ element with $56.6 \%$ (highest), $\mathrm{Si}$ is $23.1 \%$ (2nd highest), and $\mathrm{Mg}$ is $10.9 \%$ (3rd highest). It was shown that at point $1, \mathrm{Al}-\mathrm{Si}$ element was from ER4043 which from Al-Si alloy group. It was high for the atomic percentage of Mg element in $\mathrm{FZ}$ due to formation of the $\mathrm{Al}_{\mathrm{m}} \mathrm{Mg}_{\mathrm{n}}$ compound during the solidification process. Besides, point 2 shows the dark elongated grain spot which contains an atomic percentage of $\mathrm{Al}$ with $39.6 \%$ (highest), Si with $20.4 \%$ (2nd highest), and $\mathrm{Cu}$ with $6.5 \%$ (3rd highest). It was proven that point 2 also consist of Al-Si element as the major elements and $\mathrm{Cu}$ presents in the IMCs after the welding process. Other than that, point 3 represents the light grey area which was the majority area in FZ where it has the element concentration of Al with $94.5 \%$ (highest), Si with $2.4 \%$ (2nd highest), and $\mathrm{Mg}$ and $\mathrm{Zn}$ represents approximately same concentration percentages with $1.7 \%$ and $1.5 \%$, respectively. It was found that in this region, the elements

Table 6: Element concentration for welded Al 7075 using filler ER4043.

\begin{tabular}{lllllll}
\hline \multirow{2}{*}{ Point } & \multicolumn{6}{l}{ Element concentration $(\%)$} \\
\cline { 2 - 7 } & $\mathrm{Al}$ & $\mathrm{Zn}$ & $\mathrm{Mg}$ & $\mathrm{Cu}$ & $\mathrm{Fe}$ & $\mathrm{Si}$ \\
\hline 1 & 56.6 & 1.2 & 10.9 & 5.0 & 3.2 & 23.1 \\
2 & 39.6 & 1.6 & 2.1 & 6.5 & - & 20.4 \\
3 & 94.5 & 1.5 & 1.7 & - & - & 2.4 \\
4 & 25.4 & 6.7 & 2.1 & 40.7 & 2.7 & 3.9 \\
5 & 96.2 & - & 3.8 & - & - & - \\
6 & 81.0 & 9.5 & 3.5 & 6.0 & - & - \\
\hline
\end{tabular}

a.

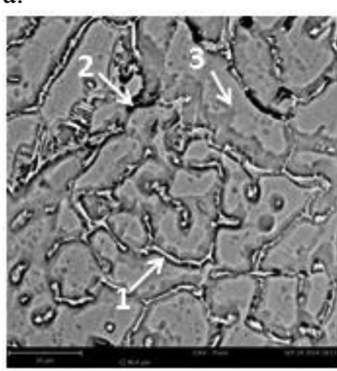

b.

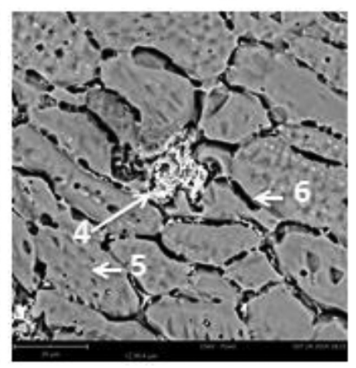

Figure 4: EDX spot analysis sample with ER4043 a. Fusion Zone b.Heat Affected Zone. 
from the parent metal such as $\mathrm{Mg}$ and $\mathrm{Zn}$ were diffused together with the elements presented in weld metal due to the formation of IMCs. It was proven that in FZ for specimen welded with ER4043, the majority element was Al-Si which is the same alloying element for this filler with a few amount of $\mathrm{Al}_{\mathrm{m}} \mathrm{Cu}_{\mathrm{n}}$ and $\mathrm{Al}_{\mathrm{m}} \mathrm{Mg}_{\mathrm{n}}$ IMCs presented.

From Figure $4 \mathrm{~b}$, point 4 shows the silverish spot which consists of percentage of element $\mathrm{Cu}$ with $40.7 \%$ (highest), Al with $25.4 \%$ (2nd highest), and $\mathrm{Zn}$ with $6.7 \%$ (3rd highest). Therefore, point 4 has element $\mathrm{Cu}$ as the majority element for the silverish spot where it was possibly from the Al 7075 parent metal. Point 5 shows the light-grey parts from the HAZ where it has the atomic percentage of $\mathrm{Al}$ with $96.2 \%$ (highest) followed by $\mathrm{Mg}$ with $3.8 \%$. It was proven that the light-grey parts were from Al-Mg alloying elements which came from the parent metal. Point 6 shows the black elongated spot in HAZ microstructure. It was found that the atomic percentage of $\mathrm{Al}$ was the highest with $81.0 \%$ along with the small percentage of its alloying element such as $\mathrm{Zn}, \mathrm{Mg}$, and $\mathrm{Cu}$ as listed in Table 6. It was proven that HAZ of sample welded using filler ER4043 has a very small amount of Si percentage. Therefore, the Al-Si compound did not produce IMC since only a small amount of Si presented in HAZ. From EDX results, FZ region for sample welded with filler ER5356 has the element of $\mathrm{Al}-\mathrm{Mg}$ due to the larger area of greyish part. For its $\mathrm{HAZ}$, it was found that it has $\mathrm{Al}-\mathrm{Zn}-\mathrm{Mg}$ element same as the Al 7075 base metal element. For sample welded with filler ER4043, Si presents higher than other elements in FZ due to the major alloying element for ER4043 was Si. HAZ region from this sample shows the element of Al-Zn-Mg same as Al 7075 base metal with less percentage of Si elements as observed from the grey area in Figure 4.

\subsection{Vicker's hardness}

Figure 5 shows the macrostructure images of samples with the UTS for both filler. The average value of hardness test was presented in Table 7. From Figure 5, it was found that the hardness value for FZ regions approximately $80.9-82.3 \mathrm{HV}$, which was lower than that of HAZ and BM with ranges of 112.7-120.7 and 103.6-109.7 HV, respectively.

The average hardness values of the FZ region for both experiments were approximately similar which 82.3 HV and 80.9 HV for experiment with filler ER5356 and ER4043, respectively. The average hardness value at HAZ position was the highest for both welded samples with $120.5 \mathrm{HV}$ and $112.7 \mathrm{HV}$ for ER5356 and ER4043, respectively. It was shown that hardness value at HAZ was higher than the other region with a hardness value ranged at 112.7-120.5 HV since the microstructure at HAZ was different due to the heat from the welding process that changes the microstructure of BM. It was presented in Table 3 where the average grain size in HAZ region was smaller than that of BM with approximately $95 \mu \mathrm{m}$ and $131 \mu \mathrm{m}$, respectively. From these results, the hardness values were increased by $9.8 \%$ and 8.7\% at HAZ for sample welded with ER5356 and ER4043, respectively. It was different at FZ where the hardness values decreased approximately $25 \%$ for both samples.

\subsection{Tensile strength}

The tensile strength result was recorded and a graph of UTS was presented in Figure 6 for welded Al 7075. Welded specimen 7 from both experiment using filler ER4043 and ER5356 recorded the highest UTS with 359 and $255 \mathrm{Mpa}$, respectively. Meanwhile, the UTS of parent metal which $590 \mathrm{Mpa}$ as shown in Figure 8. It was clearly observed from Figure 1 that at HAZ, the coarse columnar grain microstructure was produced started from the PMZ. Besides, the grain size at HAZ was also smaller than the grain size at BM for both samples. 
a.

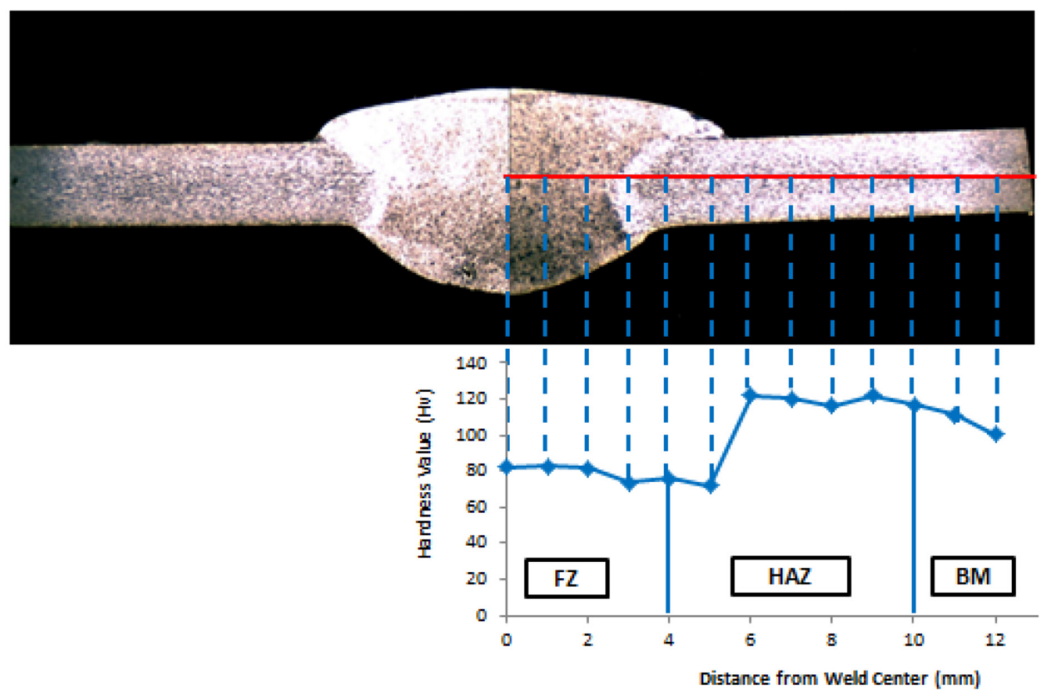

b.
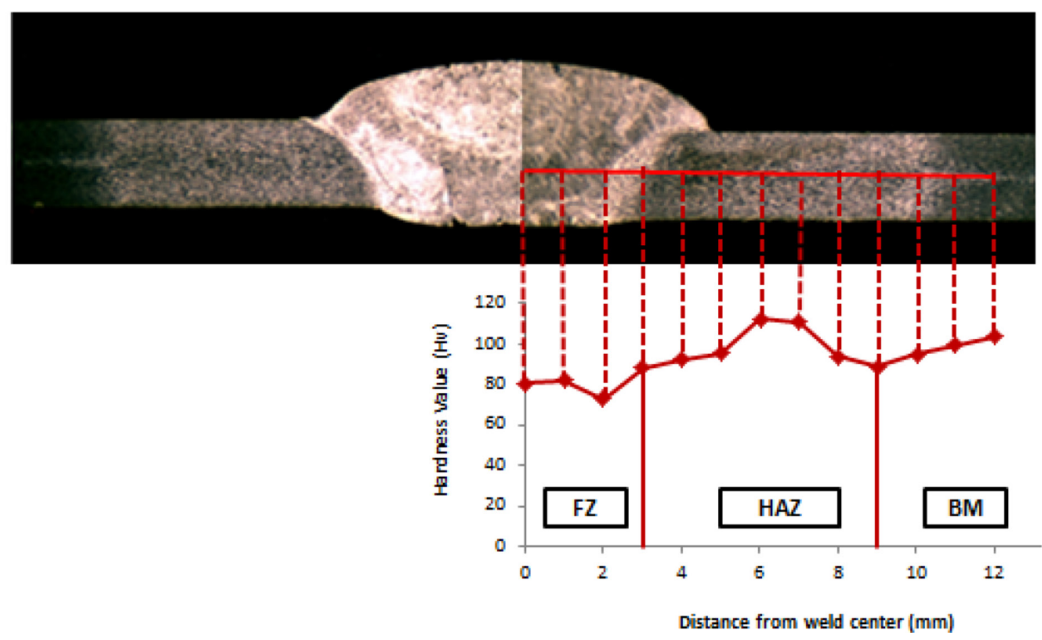

Figure 5: Macrostructure image for Vickers' hardness test a. welded with ER5356 b. welded with ER4043.

Table 7: Average Vicker's hardness value.

\begin{tabular}{llc}
\hline Position & \multicolumn{1}{l}{ Average Hardness Value (HV) } \\
\hline Filler & ER5356 & ER4043 \\
Fusion Zone (FZ) & 82.30 & 80.90 \\
Heat Affected Zone (HAZ) & 120.5 & 112.7 \\
Base Metal (BM) & 109.7 & 103.6 \\
\hline
\end{tabular}




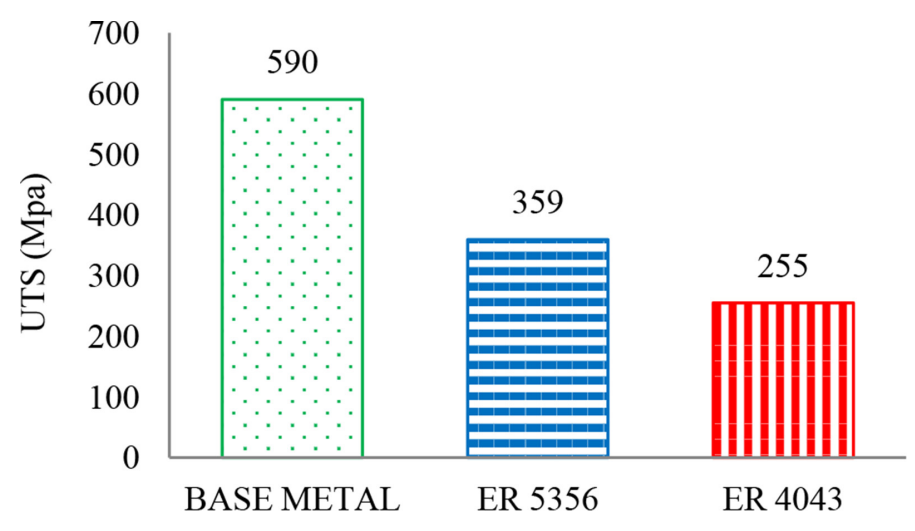

A1 7075 Specimen

Figure 6: Bar graph of ultimate tensile strength [14].

Although the grain size of FZ from ER4043 experiment was smaller than that of ER5356, the hardness value was higher for FZ from ER5356 experiment. It was due to the different group of element of filler rod where for the 4xxx series from Al-Si group, Si element was the major alloying element which has the lower hardness than the 5xxx series from Al-Mg group, which has $\mathrm{Mg}$ element as its major alloying element. The 7xxx series from $\mathrm{Al}-\mathrm{Mg}-\mathrm{Zn}$ group has the higher hardness value based on the result obtained from this testing. It was proven that the hardness value at HAZ and BM was higher than FZ zone for both samples.

The weld efficiency of ER4043 and ER5356 was 43\% and 61\%, respectively. This shows that sample welded with filler ER5356 has higher efficiency compared to sample welded with filler ER4043. This is because filler ER5356 has Mg as its major alloying elements where it is stronger than the Si. It was found that, the UTS of welded sample using ER4043 was dropped by $56 \%$ from the UTS of base metal while welded sample using ER5356 was dropped by 39\%. The sample welded using ER5356 filler proved to be a better filler metal to weld Al 7075 compared to ER4043 filler. From the hardness analysis before, FZ has lower hardness compared to BM and HAZ for both fillers. The hardness values were approximately same at each region for FZ, HAZ, and BM with values of $80-80 \mathrm{Hv}, 112.7-120.5 \mathrm{Hv}$, and 104.6109.7 HV, respectively. Although the hardness was approximately same especially at FZ, the average grain size was different for sample welded with ER5356 and ER4043 with 99.5 and $32.58 \mu \mathrm{m}$, respectively as shown in Table 3. This can be explained from the fracture analysis. It was clearly shown that the fracture position of each sample. It was proved that sample welded by ER4043 fractured at FZ where the oxide inclusion was found in big amount as shown in Figures 8 and 10. It was different compared to sample welded by ER5356 where the fracture position is at HAZ where the porosity defects observed. For ER5356, the average grain size also smaller than that of FZ and BM which is $95.28 \mu \mathrm{m}$ which very approximately same as sample welded with ER4043, $95.34 \mu \mathrm{m}$. Although the average grain size same at HAZ, the defects (oxide inclusions) which presented in FZ of sample (ER4043) contributes the sample to have the strength failure at FZ region.

\subsection{Fracture analysis}

The fracture of base metal and sample number 7 from both experiments were analysed. Figure 7 shows the load versus elongation for the tested sample. This graph shows the fracture 


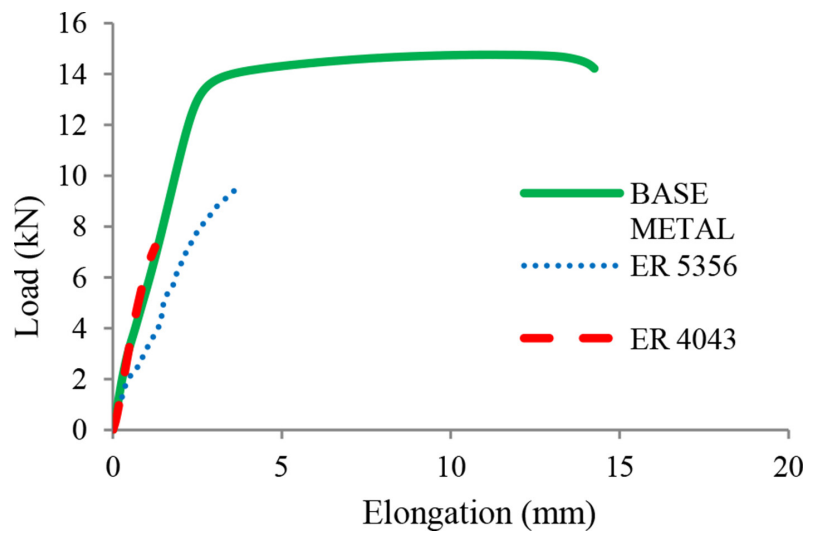

Figure 7: Load vs elongation [14].

behaviour of the tested sample. Al 7075 base metal shows the difference plot since it has plastic deformation prior to fracture. This explained that $\mathrm{Al} 7075$ has a ductile behaviour due to the plastic deformation prior to fracture. For specimen welded with filler rod ER5356 which based on element Al-Mg and ER4043 which based on Al-Si, it has no plastic deformation because of sudden fractured occurred at certain load applied. It was found that after welded with ER4043 and ER5356, brittle behaviour occurred [14]. The welded sample with ER5356 was fractured at the HAZ region. Meanwhile, the sample welded with ER4043 was fractured at the FZ region.

Figure 8 shows the macrostructure of a fractured surface for these 3 specimens which were base metal, specimen welded by ER5356 and ER4043 [14]. From this figure, it was observed that the base metal specimen was brittle fractured with a small ductile fractured behaviour since the fracture indicates some necking before it breaks. But as weld specimen

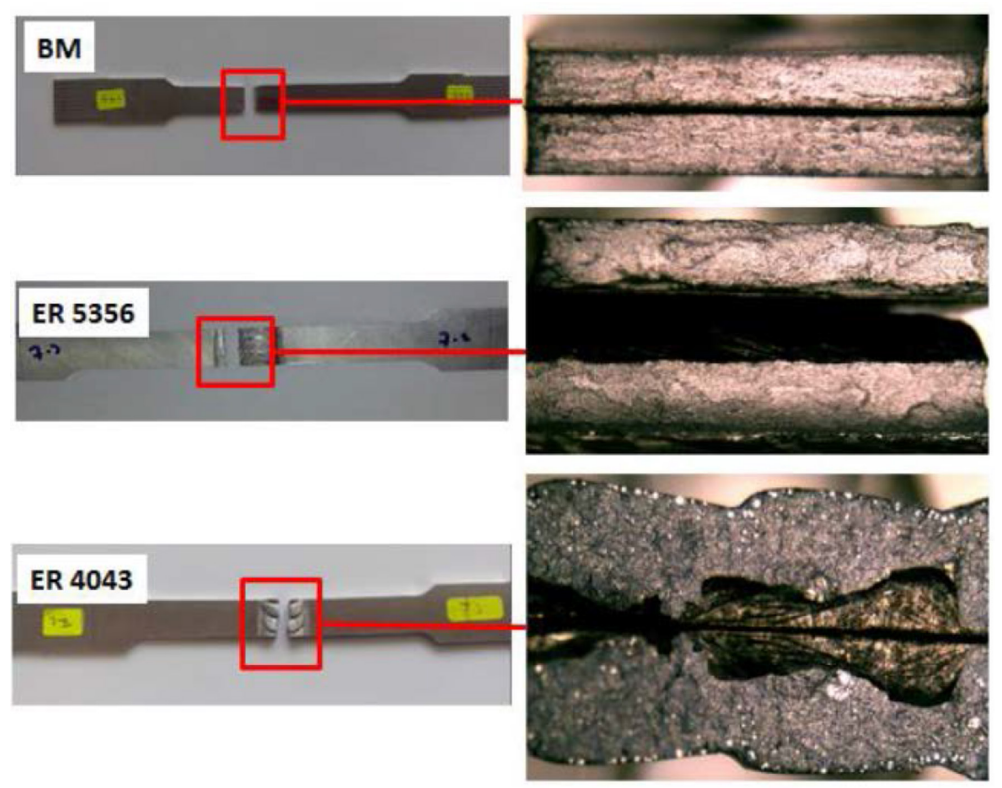

Figure 8: Macrostructure of fractured surfaces. 
welded by filler ER5356 and ER4043, both of these specimens having brittle fractured due to no necking and straight fracture observed. The fracture occurred at the Heat Affected Zone (HAZ) for sample welded by ER5356 while the fracture occurred at the Fusion Zone (FZ) for sample welded by ER4043. From the macrostructure at the fractured surface for sample welded by ER4043, it was observed that there were lot of defects in the FZ and the oxidation was clearly seen at the surface and this was one of the causes make this sample fractured at the FZ. From the sample welded by ER5356, the macrostructure at the fractured surface was observed that the behaviour of this fracture was an inter-granular brittle fracture. This type of fracture occurred due to the fracture take place along the grain boundaries at the HAZ.

Figure 9 shows the SEM image of the fracture surfaces for both samples. It was found that both samples welded with ER4043 and ER5356 fractured at this region due to the imperfection after the welding processes and it shows brittle fracture behaviour. Figure $9 \mathrm{a}$ shows that porosity presented in the HAZ and contributes to the fracture occur in the HAZ region for

a.

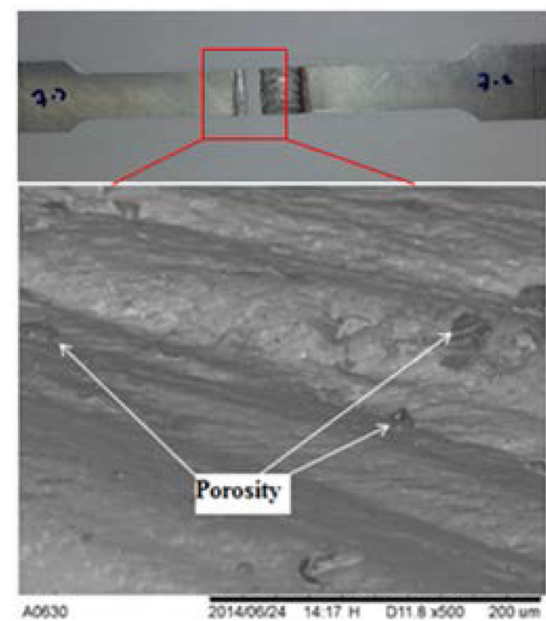

b.

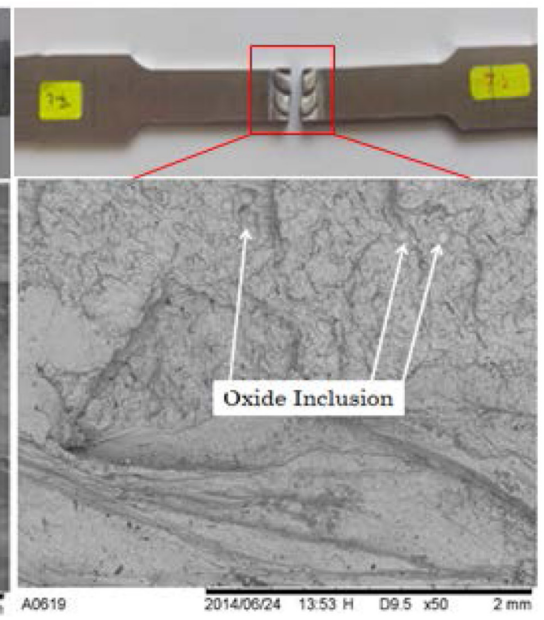

Figure 9: SEM Image of Fracture Surface a sample welded by ER5356 b sample welded by ER4043.

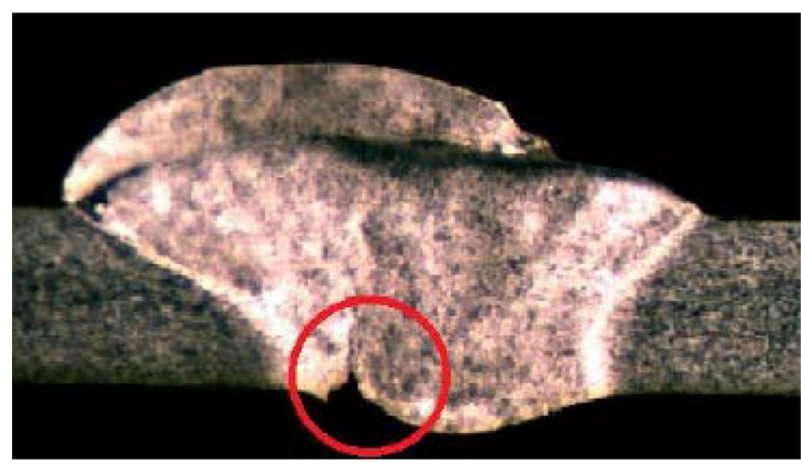

Figure 10: Lack of root fusion. 
sample welded with ER5356 filler. Meanwhile, the presence of oxide inclusion at the FZ contributes welded samples of ER4043 to fracture at the FZ region as shown in Figure 9b. It was found that sample welded with ER4043 has lower strength as it fractured at the FZ region due to the presents of oxide inclusion compared to sample welded with ER5356 which fractured at the HAZ due to the porosity defects.

\subsection{Defects analysis}

Defects in the welded specimens using both fillers were observed from microstructure image at the welded cross section. Our finding revealed that several types of defects identified such as lack of fusion, lack of fill, porosity, root crack, slag inclusion, and others were found in several welded samples.

\subsubsection{Sample welded by ER5356}

Figures 10 until 12 show the defects observed visually on sample welded by ER5356. From Figure 10 shows the lack of root fusion from specimen number 8 . The macrostructure was observed where it was found that the left side of the sample's root was not melted. This type of defect was also known as the lack of root fusion defect due to the fusion zone was not completely melt the root of the joint which could contribute to lower joint strength.

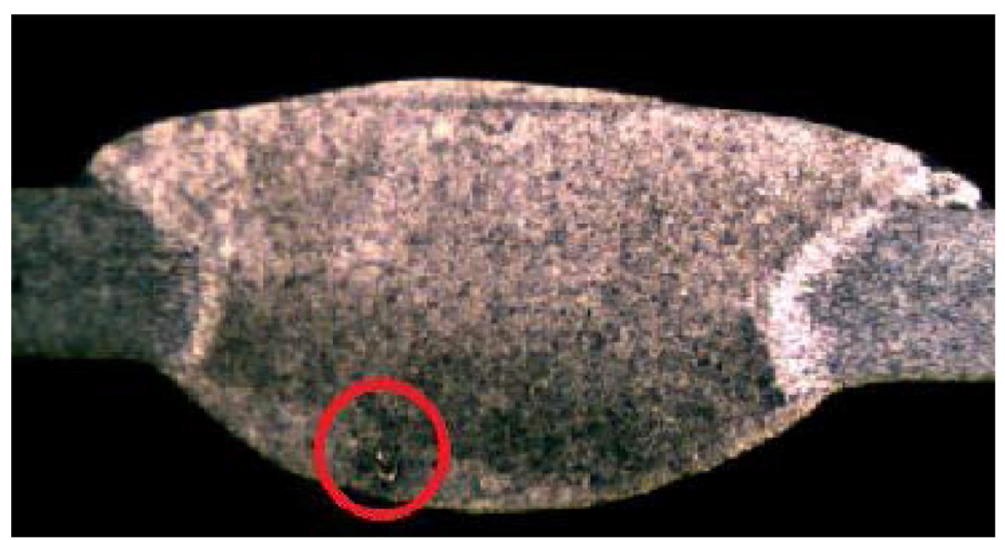

Figure 11: Slag inclusion.

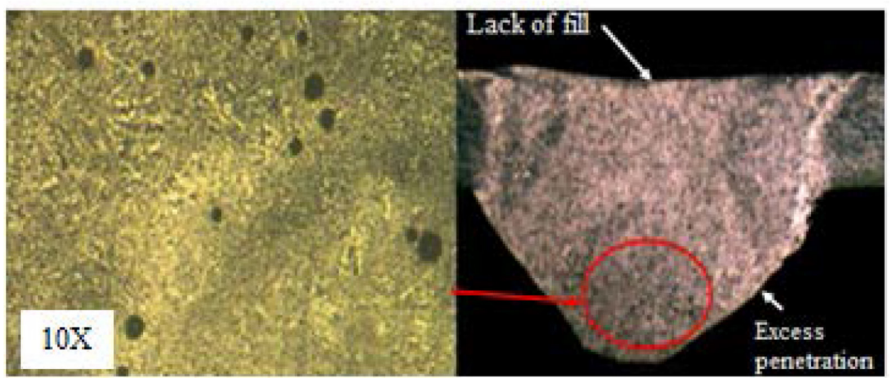

Figure 12: Porosity, lack of fill, and excess penetration. 
Figure 11 shows the microstructure of welded cross section for specimen number 7. It was observed that slag inclusion defects presented in the weld metal after the welding process. Slag was normally seen either continuous or discontinuous at elongated line in the weld metal region and it occurs when there was non-metallic solid materials were entrapped in the fusion zone. Same situation happens with the porosity defects, slag inclusion defects was one of the discontinuities in the weld joint where it was the interruption during the welding process. However, slag inclusion was different with the gas pore defect due to differences in their shape and size.

Figure 12 reveals the porosity defect, lack of fill, and excess weld penetration in specimen number 1. For the microstructure under scale $50 \mu \mathrm{m}$ with 10 times magnification, it was observed that there was some pores in the Fusion Zone (FZ) as it can be a caused in strength failure. Gas was trapped into the weld metal during the solidification process due to the flow of turbulence and lack of liquid metal feeding. For the inadequate weld reinforcement defect on the weld bead, it was observed that the thickness of the weld metal area deposited less than the base metal thickness. This behaviour also was known as lack of fill defect. The cause of this defect was excessive heating and melting of pass during the deposition. From this figure also, the excess weld penetration was observed as the second defect founded in the weld metal. The projection of root penetration bead was higher than the specified limit and this defect can be continuously or local. Excess weld penetration occured when the heat input was high during welding process. The other cause produce this defect was when the incorrect weld prepartion such as the material with excessive root gap or thin edge preparation.

\subsubsection{Sample welded by ER4043}

Figures 13 until 16 show the defects observed visually on sample welded by ER4043. Figure 13 shows that specimen number 2 from sample welded with filler ER4043 have linear misalignment defect due to the welded specimen was not parallel during the welding process. The causes of this defect were when there were inaccuracies in the assembly procedures preparation and there was excessive "out of flatness".

Figure 14 indicates the porosity defect in specimen number 7 . At scale $50 \mu \mathrm{m}$ with 10 times magnification, it was observed that there were some pores in the Fusion Zone (FZ) as it

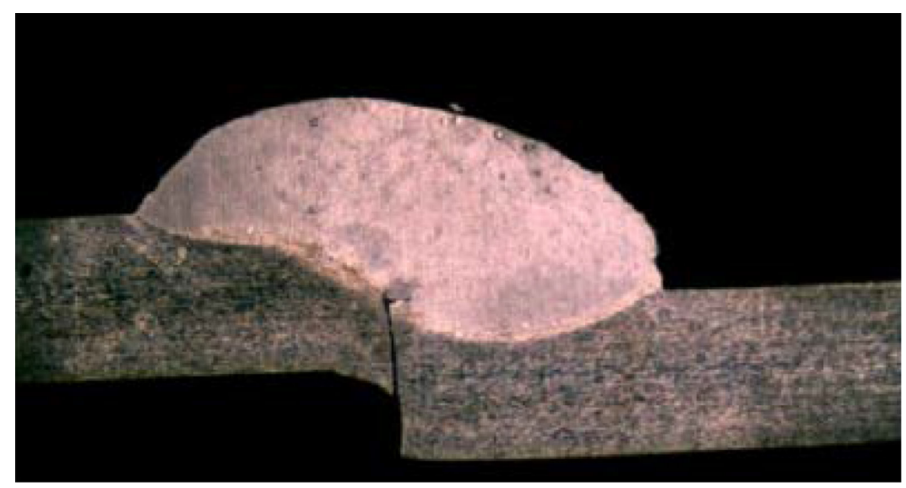

Figure 13: Linear misalignment. 
can be a big reason in strength failure. From the fracture analysis before, specimen 7 welded with ER4043 was fractured at the fusion zone and the strength was lower than the specimen welded by ER5356. Gas trapped into the weld metal during the solidification process due to the flow of turbulence and lack of liquid metal feeding.

Figure 15 shows that there were oxide inclusions in the fusion zone of specimen number 6 . Some oxide particles occurred in the keyhole vapor due to the unstable flow of keyhole that entraps the air or even the shielding gas. The figure also provides the image of the crack at the

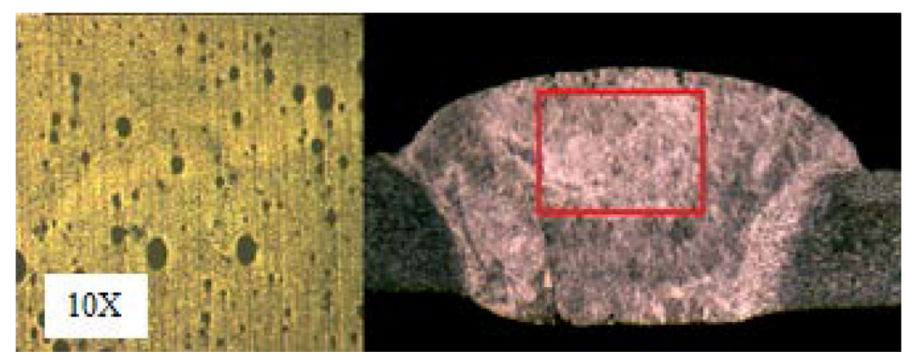

Figure 14: Porosity defect.

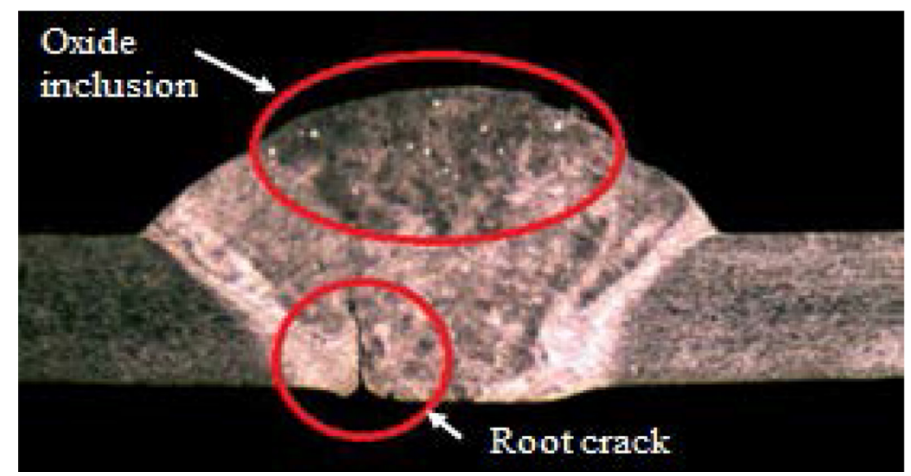

Figure 15: Oxide inclusion and root crack. 6

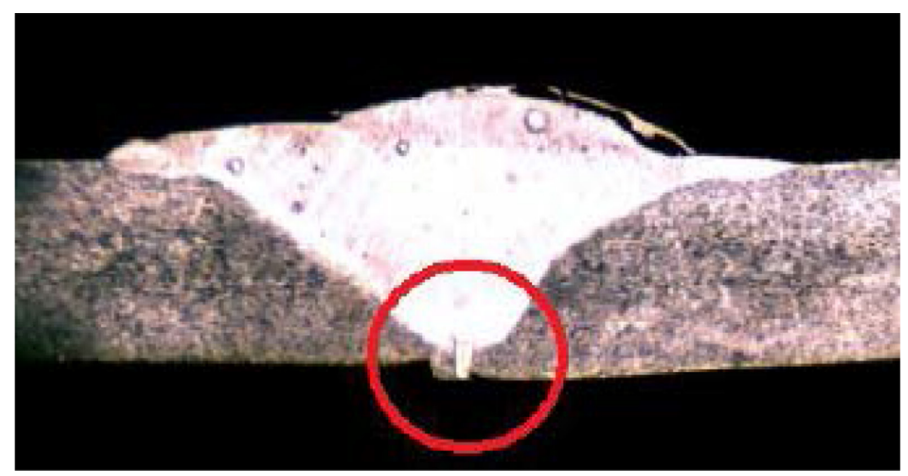

Figure 16: Lack of penetration. 11 
root in the fusion zone. This defect gives effect towards the position of fracture occurred from the tensile test where the specimen fractured at the weld metal as explained in the fracture analysis as illustrated in Figure $9 b$.

Figure 16 the cross section macrostructure image of specimen number 11. It was found that lack of penetration defect was occured due to the failure of weld metal to penetrate the joint that allows the crack occured at the welded joint. This defect also contributes to the fracture occured at the welded joint from the tensile test since the joint was not enough strength especially at the center of welded zone.

\section{CONCLUSION}

This study has found that generally filler metal plays important role in arc welding process especially contributes to the aluminium alloys joint which is very sensitive. From this experiment for the effect of filler ER4043 and ER5356 toward the welded Al 7075, the important conclusions were drawn include:

1. Microstructure sample in FZ was different for both fillers in term of their grain size were observed. Small IMC compound such as $\mathrm{Al}_{\mathrm{m}} \mathrm{Cu}_{\mathrm{n}}$ produced at the $\mathrm{FZ}$ for both fillers from EDX spot analysis were proved.

2. The hardness strength at the FZ region was lower compared to HAZ and BM for both fillers, while the welding efficiency welded by ER5356 was higher than welded by ER4043 from mechanical testing was investigated.

2. Fracture at HAZ and FZ occur for welded sample by ER5356 and ER4043, respectively. Both samples were brittle fractured. A large number of pores and oxide inclusions present as defects contribute the samples to break at the fracture position.

\section{REFERENCES}

[1] Fakuda, T., Weldability of 7000 series aluminium alloy materials. Welding International, 26(4), pp. 256-269, 2012. http://dx.doi.org/10.1080/09507116.2011.590665

[2] Tu, J.F. \& Paleocrassas, A.G., Fatigue crack fusion in thin-sheet aluminum alloys AA7075-T6 using low-speed fiber laser welding. Journal of Materials Processing Technology, 211, pp. 95-102, 2011.

http://dx.doi.org/10.1016/j.jmatprotec.2010.09.001

[3] Stano, S., Pfeifer, T. \& Różański, M., Modern technologies of welding aluminium and its alloys. Welding International, 28(2), pp. 91-99, 2014. http://dx.doi.org/10.1080/09507116.2012.708478

[4] Ema, M., Tensile strength of MIG-welded 7000 series aluminium alloy extrusions. Welding International, 22(10), pp. 661-668, 2008.

http://dx.doi.org/10.1080/09507110802460895

[5] Budinski, K.G. \& Budinski, M.K., Engineering Materials, Properties and Selection, 8th edn., Prentice-Hall, 2005.

[6] Fortain, J.M. \& Gadrey, S., How to select a suitable shielding gas to improve the performance of MIG and TIG welding of aluminium alloys. Welding International, 27(12), pp. 936-947, 2013.

http://dx.doi.org/10.1080/09507116.2012.753257 
[7] Sivashanmugam, M., Manoharan, N., Ananthapadmanaban, D. \& Ravi Kumar, S., Investigation of microstructure and mechanical properties of GTAW and GMAW joints of aa7075 aluminum alloy. International Journal on Design and Manufacturing Technologies, 3, pp. 56-62, 2009.

http://dx.doi.org/10.18000/ijodam.70063

[8] Miyasaka, F., Okuda, T. \& T. Ohji, Effect of current wave-form on AC TIG welding of aluminium alloys. Welding International, 19(5), pp. 370-374, 2005.

http://dx.doi.org/10.1533/wint.2005.3437

[9] Temmar, M., Hadji, M., \& Sahraoui, T., Effect of post-weld aging treatment on mechanical properties of tungsten inert gas welded low thickness 7075 aluminium alloy joints. Material and Design, 32, pp. 3532-3536, 2011.

http://dx.doi.org/10.1016/j.matdes.2011.02.011

[10] Balasubramanian, V., Ravisankar, V. \& Madhusudhan Reddy, G., Influences of pulsed current welding and post weld aging treatment on fatigue crack growth behaviour of AA7075 aluminium alloy joints. International Journal of Fatigue, 30, pp. 405-416, 2008.

http://dx.doi.org/10.1016/j.ijfatigue.2007.04.012

[11] Ema, M., Tensile strength of MIG-welded aluminium alloys for structures. Welding International, 22(4), pp. 199-205, 2008.

http://dx.doi.org/10.1080/09507110802117537

[12] Zhao, P.Z. \& Tsuchida, T., Effect of fabrication conditions and $\mathrm{Cr}, \mathrm{Zr}$ contents on the grain structure of 7075 and 6061 aluminum alloys. Materials Science and Engineering, 499, pp. 78-82, 2009.

http://dx.doi.org/10.1016/j.msea.2007.09.094

[13] Cao, X., Wallace, W., Immarigeon, J.P. \& Poon, C., Research and progress in laser welding of wrought aluminum alloys. II. metallurgical microstructures, defects, and mechanical properties. Materials and Manufacturing Processes, 18(1), pp. 23-49, 2003.

http://dx.doi.org/10.1081/AMP-120017587

[14] Ishak, M., Salleh, M.N.M., Aisha, S.R. \& Shah, L.H., The effect of ER 4043 and ER 5356 filler metal on welded Al 7075 by metal inert gas welding. 7th International Conference on Computational Methods and Experiments in Materials Characterisation, 2015. 